\title{
Effects of Surface Properties of Vertical Textiles Indoors on Particle Deposition: A Small-scale Chamber Study
}

\author{
Yan Wang ${ }^{1}$, Angui Li ${ }^{1}$, Xiaowei Fan ${ }^{2 *}$, Shiyan Lu$^{3}$, Liangyue Shang ${ }^{3}$ \\ ${ }^{1}$ School of Environmental and Municipal Engineering, Xi'an University of Architecture and Technology, Xi'an, Shaanxi \\ 710055, China \\ ${ }^{2}$ Department of Architectural Engineering, Jiyuan Vocational and Technical College, Jiyuan, Henan 459000, China \\ ${ }^{3}$ School of Energy and Environmental Engineering, Zhongyuan University of Technology, Zhengzhou, Henan 450007, China
}

\begin{abstract}
The present study aims to further understand the effect of surface properties of vertical textiles indoors on the particle deposition. A $512 \mathrm{~L}$ cubic aluminum experimental chamber was built to obtain the deposition loss rate coefficients for $0.37,0.54,0.75,0.9,1.3$, and $1.6 \mu \mathrm{m}$ particles under three different airflow conditions. Eight curtain fabrics-four window voile fabrics and four curtain cloths-were selected as the deposition surfaces in investigating the effect of fabric porosity on particle deposition. The total fabric porosity can be roughly divided into inter-yarn porosity and inter-fiber porosity. The experimental results reveal that both the near-surface airflow velocity and the particle size affect the deposition loss rate coefficient. The trend of the deposition loss rate coefficient with increasing inter-yarn porosity differs from that with increasing inter-fiber porosity.
\end{abstract}

Keywords: Deposition loss rate coefficient; Curtain; Fine particle; Fabric; Porosity.

\section{INTRODUCTION}

Atmospheric particle pollution, an international issue caused by the large increase in anthropogenic emissions, has recently received widespread attention due to its adverse effects on human health and visibility (Xiao et al., 2011; Qiao et al., 2016; Tang et al., 2016). Indoor particle concentration can be directly affected by the outdoor particles because a large fraction of indoor aerosol particles originate from outdoor air (Vette et al., 2001; Hussein et $a l ., 2005)$. It is estimated that people may spend about 80 $90 \%$ of their life indoors; meanwhile, many studies have shown that the air quality in buildings is less satisfying than the outdoor air (Delgado-Saborit et al., 2011; Azar et al., 2016; Liu et al., 2018b). Therefore, the air quality in indoor environment is of equal or greater importance than outdoor air quality to human health (Lai et al., 2002; Liu et al., 2018a). Deposition onto surfaces is one of the fate for particles in indoor air (Lai and Nazaroff, 2000; Chen et al., 2014). Particle deposition is beneficial for human health, because it can reduce indoor airborne particle concentrations and result in reduced inhalation exposures. However, it can

\footnotetext{
* Corresponding author.

Tel.: +86 13783717029; Fax: +86-391-6621000

E-mail address: xwfan66@sina.com
}

also lead to a series of detrimental consequences, such as soiling of artwork and damage to electronic equipment (Nazaroff and Cass, 1991; Weschler et al., 1996).

Particle deposition on indoor surfaces is a complex problem because it is related to many factors (Nazaroff et al., 1993). Experimental studies of particle deposition on real indoor surfaces have been extensively performed in small-scale chambers or real houses (Thatcher et al., 2002; Hamdani et al., 2008; Chen and Li, 2014). In the analysis of factors influencing particle deposition in indoor environments, Zhao and $\mathrm{Wu}$ (2007) reported that rougher surface may lead to larger particle deposition velocity when the particle size is small. Abadie et al. (2001) determined experimentally the deposition constants for several wall textures found in buildings, and showed the importance of taking particle size, wall texture and orientation into consideration in the prediction of indoor particle concentration. In addition, the deposition velocity of particles on smooth glass plates and sandpaper with different roughness were measured by Lai and Nazaroff (2005), and they observed that particle deposition onto smooth and rough vertical surfaces increases with particle size for most conditions. Therefore, it can be concluded from these literatures that particle deposition may be strongly affected by the surface characteristics.

Textile fabrics, such as curtains, carpets and wall cloths, have been widely used as decorative materials in indoor environment in recent years. However, only a small 
amount of literatures studying particle deposition indoors referred to these textile surfaces (Afshari and Reinhold, 2008; Hussein et al., 2009b). As a discontinuous porous material, textile fabric was usually treated as rough surface and characterized only with roughness in previous studies (Abadie et al., 2001; Lai, 2002; Wang, 2012). But, the measurement and characterization of the surface roughness for textile materials, owing to their special properties of softness and easy deformation, should be different from that for other indoor surfaces such as glass and wood. Wang et al. (2018) have introduced the special method for roughness measurement of textile material, as well as the effect of roughness on particle deposition. However, because of the complexity of surface properties for textile materials, it is not enough to describe the textile surface with only roughness in the study of particle deposition.

As a continued work of Wang et al. (2018), the present study aims to further investigate the particle deposition on vertical textile materials in a small-scale chamber. It is well known that there are usually many voids in the surface and interior of the textile material, which may affect the airflow velocity and concentration distribution of particles near the textile surface. Therefore, it is necessary to investigate the effect of these voids in textile material on particle deposition. This is the main goal of this study and has never been published and intensively analyzed in previous studies according to our knowledge.

\section{MATERIAL}

As an important household textile, more and more curtains have appeared in the indoor environment of residences, hotels, offices, etc. Furthermore, curtains can trap large amounts of particles both from indoor and outdoor environment because they are hung beside windows, the interface of indoor and outdoor environment. Therefore, the particle deposition on vertical curtain surfaces was investigated in this study. Generally speaking, curtain can be divided into three layers according to its structure and application, that is inner, middle, and outer layer. The outer layer of the curtain is very thin, which is usually called window voile. Due to the characteristics of high light transmittance and air permeability, the window voile is usually loose in structure and has a large number of via holes on its surface. However, the middle and inner layers of the curtains, which can be called curtain cloths, are usually thick and compact in structure due to their features of shading and heat insulation. In this study, eight curtain fabrics made of polyester, including 4 window voile fabrics (numbered by A-D) and 4 curtain cloths (numbered by E-H), were selected as the deposition surfaces and tested in a small-scale chamber. The microscope images of the samples are shown in Fig. 1.

Since textile fabrics are discontinuous materials, they have void spaces or pores that may account for a significant fraction of their total volume, and therefore finite porosities (Rebenfeld and Miller, 1995). In a fabric, pores may be situated in the fibers, between fibers in the yarns, and between yarns in the fabric. The porosity of textile is an index reflecting the pore volume of fabric. The yarn diameter, surface formation techniques, and number of yarn threads per unit area are the main factors affecting the porosity of textiles. Porosity can be defined as the ratio of the projected geometrical area of the opening across the

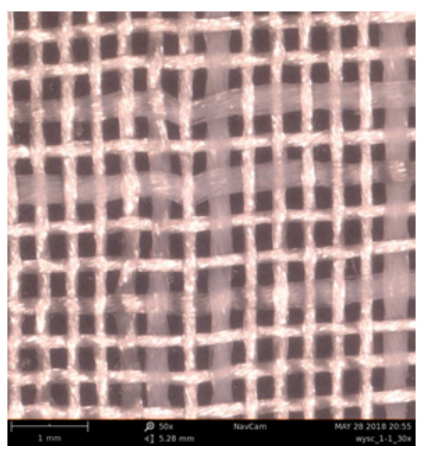

(A)

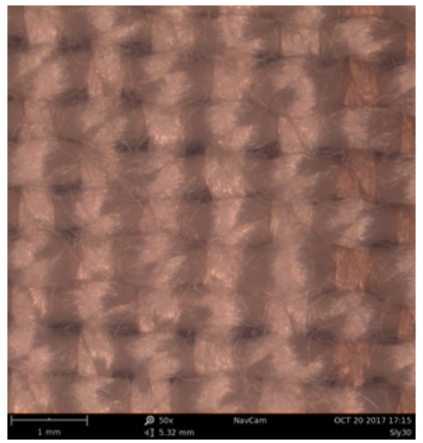

(E)

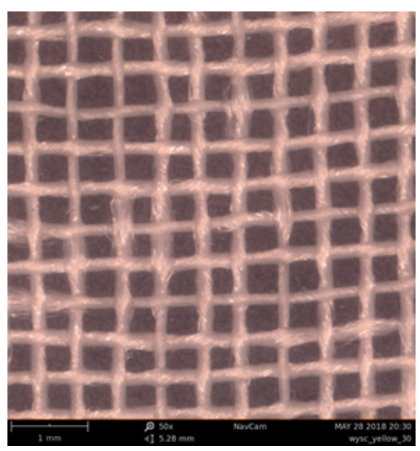

(B)

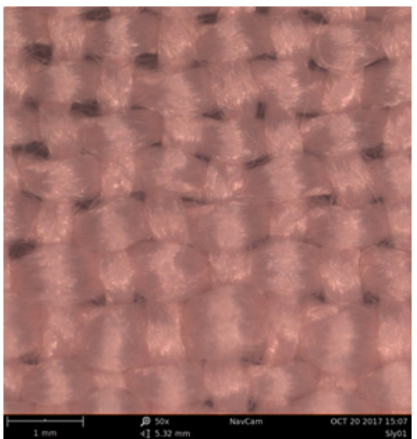

(F)

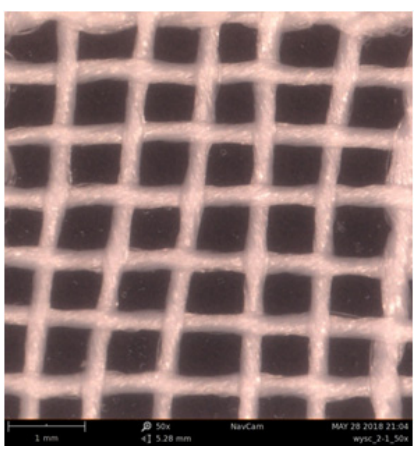

(C)

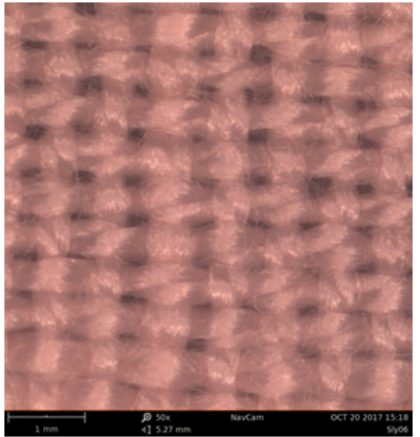

(G)

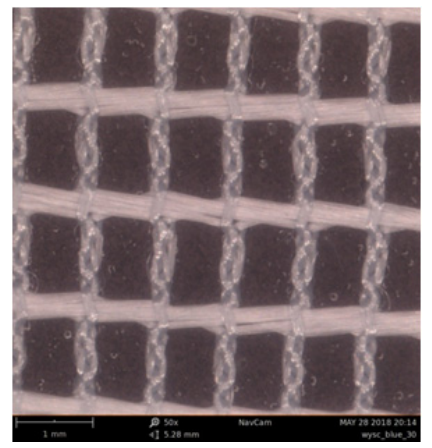

(D)

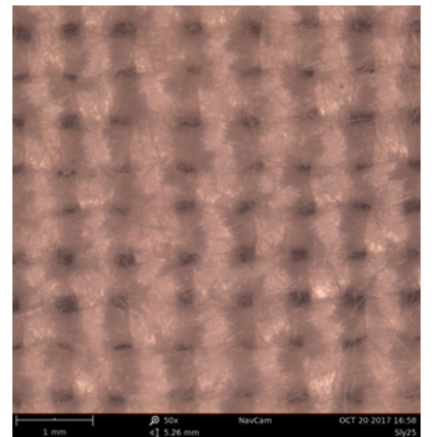

(H)

Fig. 1. Microscope photographs of the samples. 
material to the total area of the material (Çay et al., 2007):

$$
\varepsilon_{1}=\frac{\text { open pore area }}{\text { total area }}=\frac{P_{1} \times P_{2}}{\left(P_{1}+d_{1}\right)\left(P_{1}+d_{2}\right)} \times 100 \%
$$

where $\varepsilon_{1}$ is fabric porosity (\%), $P_{1}$ is the distance between warp threads ( $\mathrm{mm}), P_{2}$ is the distance between weft threads $(\mathrm{mm}), d_{1}$ is the diameter of the warp yarn $(\mathrm{mm})$, and $d_{2}$ is the diameter of the weft yarn $(\mathrm{mm})$. Note that the parameter $\varepsilon_{1}$ in Eq. (1) is the geometrical expression of porosity, which gives only the inter-yarn porosity of the fabrics. In addition, there is another expression for porosity, that is the fraction of void space in a porous medium (Hsieh, 1995):

$\varepsilon_{2}=\left(1-\frac{\rho_{a}}{\rho_{b}}\right) \times 100 \%$

where $\rho_{a}$ is the fabric density $\left(\mathrm{g} \mathrm{cm}^{-3}\right)$ and $\rho_{b}$ is the fiber density $\left(\mathrm{g} \mathrm{cm}^{-3}\right)$. Fabric density is calculated by dividing the fabric weight per unit area, by fabric thickness. The parameter $\varepsilon_{2}$ in Eq. (2) is the total porosity including not only the inter-yarn porosity but also the inter-fiber porosity of the fabric.

Fig. 2 illustrates the micro-morphology of window voile and curtain cloth using the SEM photographs of Samples A and $\mathrm{F}$ as examples, respectively. The selected window voile samples in this study were woven from single yarns of polyester filament. It can be seen from Fig. 2(a) that the filament fibers in the yarn are closely combined with each other, and therefore the void spaces between these filaments are very small. However, in order to ensure the high light transmittance and air permeability, there are always large gaps between the yarns of window voile fabrics, which can reach almost 1-2 times the diameter of the yarn. Therefore, the porosities of the window voile samples in this study were determined according to Eq. (1), and calculated by the method of image processing using the software of Image J. To elaborate, a window voile fabric with a black paper on its back was scanned with a scanner to obtain an image firstly. And then, the obtained image was magnified as much as possible on the premise of maintaining clear boundary between the yarns and voids. Following that, the magnified image was opened in the software of Image $\mathrm{J}$ and converted into an 8-bit gray image. An appropriate threshold in the software was then set manually to convert the obtained gray image into a corresponding binary image, so that the software can accurately identify the area of white region (representing yarns) and black region (representing pores) in the binary image. Finally, the Image $\mathrm{J}$ software can automatically calculate the ratio of the sum area of the black region to the whole image area (the sum area of white and black region), that is, the fabric porosity of window voile sample.

The samples of curtain cloths, which are relatively thick and compact in thickness and structure, were woven from ply yarns that are made from twisting of staple-fiber yarns. The SEM photograph in Fig. 2(b) shows that there are a large number of voids not only between the ply yarns, but also between the staple-fibers of the curtain cloths. Therefore, the porosity of the curtain cloth samples in this study should be the total porosity and calculated according to Eq. (2). Here, the mean density of the polyester fiber $\left(\rho_{b}\right)$ in Eq. (2) is accepted as $1.38 \mathrm{~g} \mathrm{~cm}^{-3}$. The porosities and measured structural parameters of Samples A-H are shown in Table 1, where SMD and L are the surface roughness and thickness of these textile samples, respectively.

\section{METHOD}

\section{Experimental Device}

Detailed information about the experimental device and particle generation can be found elsewhere (Wang et al., 2018), hence only a brief description will be presented here. Experiments in this study were conducted in a smallscale chamber made of aluminum, which consists of a cube of side $0.8 \mathrm{~m}$ and a door in one of the vertical faces. Figs. 3(a) and 3(b) show the schematic diagram of the overall experimental facilities and the factual picture of the

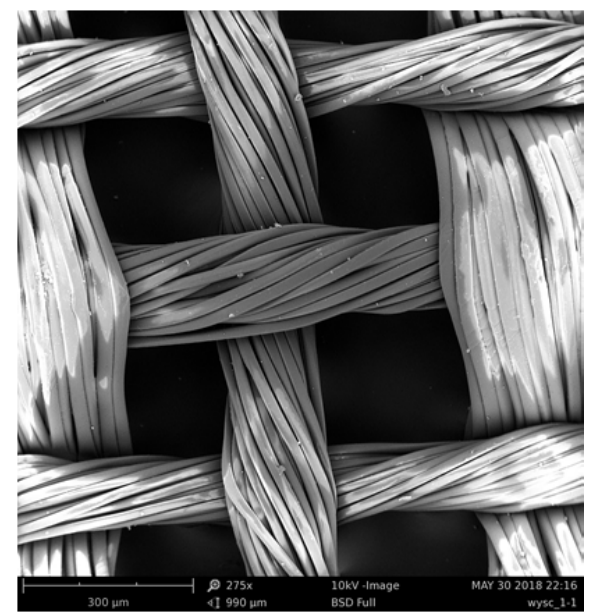

(a) Sample-A

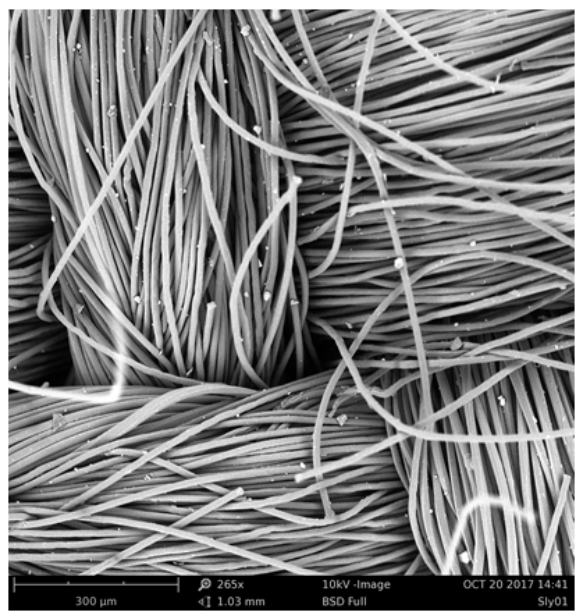

(b) Sample-F

Fig. 2. SEM photographs of samples A and F. 
Table 1. Porosities and structural parameters for samples A-H.

\begin{tabular}{lllllllll}
\hline Sample No. A & B & C & D & E & F & G & H \\
\hline$\varepsilon_{1}(\%)$ & $28.68 \pm 0.93$ & $40.61 \pm 0.83$ & $42.76 \pm 0.42$ & $50.17 \pm 0.57$ & $2.07 \pm 0.18$ & $5.19 \pm 0.59$ & $5.15 \pm 0.54$ & $4.61 \pm 0.42$ \\
$\varepsilon_{2}(\%)$ & - & - & - & - & $72.03 \pm 1.53$ & $66.64 \pm 0.13$ & $65.70 \pm 0.47$ & $63.22 \pm 0.57$ \\
$P_{1}(\mathrm{~mm})$ & $0.31 \pm 0.01$ & $0.41 \pm 0.01$ & $0.89 \pm 0.04$ & $1.05 \pm 0.04$ & - & - & - & - \\
$P_{2}(\mathrm{~mm})$ & $0.22 \pm 0.02$ & $0.33 \pm 0.02$ & $0.46 \pm 0.06$ & $0.67 \pm 0.03$ & - & - & - & - \\
SMD $(\mu \mathrm{m})$ & $2.58 \pm 0.40$ & $2.54 \pm 0.12$ & $2.77 \pm 0.22$ & $1.69 \pm 0.06$ & $13.79 \pm 0.59$ & $13.70 \pm 0.72$ & $13.36 \pm 0.81$ & $12.94 \pm 1.02$ \\
L $(\mathrm{mm})$ & $0.29 \pm 0.01$ & $0.26 \pm 0.01$ & $0.35 \pm 0.01$ & $0.28 \pm 0.01$ & $0.62 \pm 0.03$ & $0.64 \pm 0.03$ & $0.46 \pm 0.01$ & $0.54 \pm 0.02$ \\
\hline
\end{tabular}

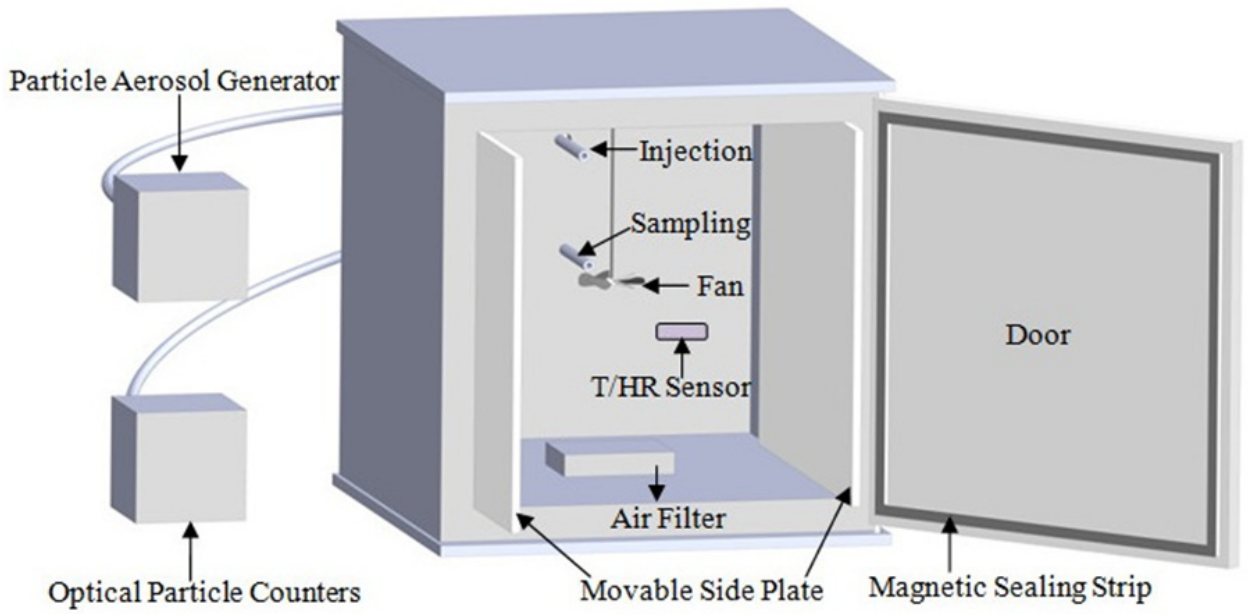

(a)

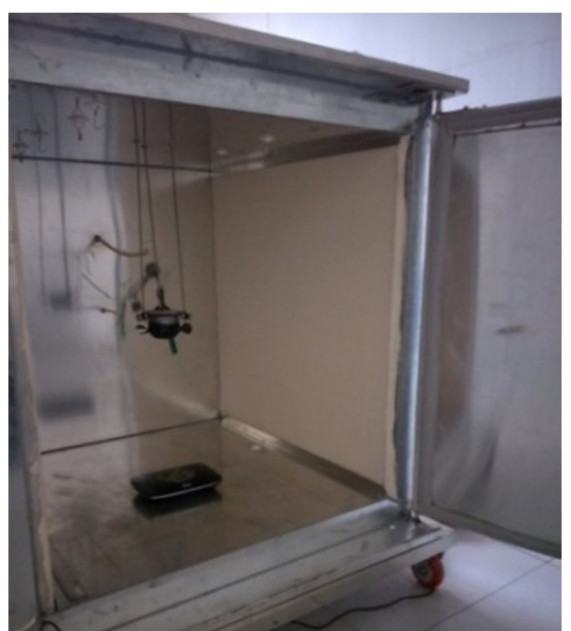

(b)

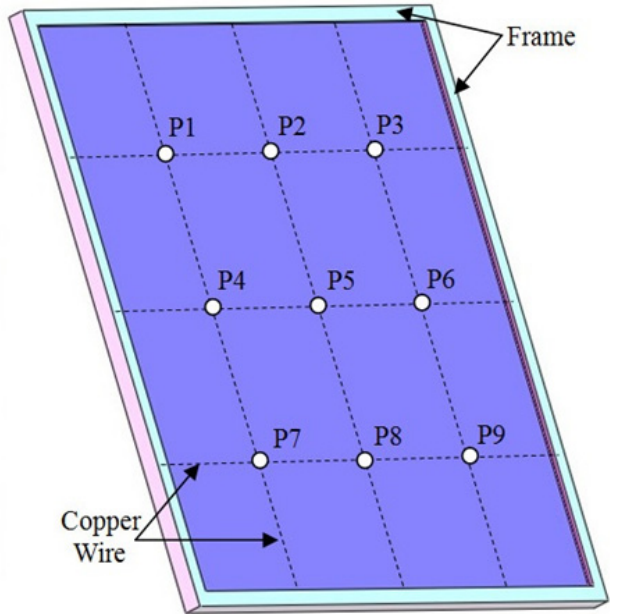

(c)

Fig. 3. Experimental setup and facilities. (a) Schematic view of the experimental facilities. (b) Photograph of the experimental chamber. (c) Details of the movable side plate and locations of the airflow velocity measurement.

test chamber, respectively. A six-bladed fan was suspended $0.4 \mathrm{~m}$ away from the center of the ceiling and could produce an upward air stream to control the air circulation in the chamber. Two movable side plates shown in Fig. 3(c) were designed to make it easy to stick the soft textile materials to the vertical walls of the chamber. A magnetic sealing strip was fixed on the door of the chamber, and meanwhile the corresponding position of the chamber was covered by an iron plate. Therefore, the magnetic sealing strip could tightly attach to the iron plate when the door of the chamber was closed, thus ensure the good sealing effect of the chamber. In addition, all six external walls of the chamber were insulated by a 5-cm-thick polyurethane foam to maintain good thermal stability inside the test chamber.

In order to ensure that the deposition of differently sized particles was under the same environmental conditions (temperature, relative humidity and electrostatic force), particles were first separated from a blended solution of monodisperse polystyrene latex microspheres of diameters $0.37,0.54,0.75,0.9,1.3$, and $1.6 \mu \mathrm{m}$ in deionized water using a particle generator (ATM 220, Topas). After passing through a drying tube containing silica gel, these particles 
were then injected into the chamber through an injection tube located at the back wall of the chamber. Meanwhile, a sampling tube was also located at the geometric center of the back wall and connected to an optical particle counter (Model 11-A, GRIMM) to measure the particle concentration inside the chamber. Also, there was a mini air filter at the center of the bottom of the chamber to purify the air inside the chamber before experiments. In addition, a sensor that can provide real-time measurement of temperature and relative humidity of the air was placed at the lower part of the chamber.

\section{Experimental Procedure}

The detailed experimental procedures are not repeated here but can be found in Wang et al. (2018). In brief, prior to each experiment, the tested samples and internal surfaces of the chamber were cleaned thoroughly to avoid the crossexperiment contamination. And then, the tested samples, which had similar moisture content because they had been placed in the same environment of temperature and relative humidity for at least $24 \mathrm{~h}$, were fixed on the frame of the active side plates outside and then sent into the chamber through two slide rails. After these preparation works, the mini air filter at the bottom of chamber was turned on and the door of the chamber was closed immediately. The air filter remained in operation until the total particle count in the chamber was close to zero. And then, the air filter was turned off and the fan was turned on remotely. The particles produced by the aerosol generator were then injected into the chamber continuously until the total particle count reached the target value. This injection process was estimated not to exceed $3 \mathrm{~min}$. Subsequently, the deposition process began immediately and ended after a period of time. At least nine experiments have been conducted for each sample, i.e., a minimum of three repeated measurements for each of the three different fan angular velocities.

Deposition is an important factor affecting the concentration and size distribution of indoor particles. The indoor particle pollution models, which are based on the concept that mass is conserved, have been established to predict the potential health risks of the indoor particles. Assuming well-mixed core region of the indoor environment and absence of the indoor sources as well as the active removal by the air filter, the rate of change of indoor particle concentration with time can be described as follows (Abadie et al., 2001):

$$
\frac{d C_{i}}{d_{t}}=\lambda_{r} C_{O}-\lambda_{r} C_{i}-\lambda_{d e} C_{i}+\lambda_{R} D_{i}
$$

where $C_{i}$ is the indoor particle concentration (part $\mathrm{m}^{-3}$ ), $C_{O}$ is the outdoor particle concentration (part $\mathrm{m}^{-3}$ ), $D_{i}$ is the deposited particle concentration (part $\mathrm{m}^{-3}$ ), $\lambda_{r}$ is the air change rate of the room $\left(1 \mathrm{~h}^{-1}\right), \lambda_{d e}$ is the deposition loss rate coefficient $\left(1 \mathrm{~h}^{-1}\right), \lambda_{R}$ is the particle resuspension coefficient $\left(1 \mathrm{~h}^{-1}\right)$, and $\mathrm{t}$ is the time $(\mathrm{h})$. Because of the difficulty in distinguishing the effects of deposition and resuspension, the parameter $\lambda_{d}$ was introduced to evaluate their total effect in practice. Thus, considering the good seal of the chamber, the solution of Eq. (3) becomes:

$C_{i}(t)=C_{i}(0) \times \exp \left(-\lambda_{d} \times t\right)$

Therefore, the deposition loss rate coefficient $\lambda_{d}$ can be calculated by the linear regression of measured particle concentration according to Eq. (4). In addition, there is a limitation of the maximum particle concentration for the optical particle counter used in this study $\left(\leq 2000\right.$ part $\left.\mathrm{cm}^{-3}\right)$. However, too low particle concentration in the chamber $\left(\leq 500\right.$ part $\left.\mathrm{cm}^{-3}\right)$ may cause high fluctuations in the measurement results, which is possibly due to instrumental artifacts or inhomogeneous distribution of aerosol particles inside the chamber (Hussein et al., 2009a). Therefore, the initial particle concentration in the chamber after the injection was determined to be 1000 part $\mathrm{cm}^{-3}$. As reported by $\mathrm{Xu}$ et al. (1994), the effect of coagulation on the particle concentration was negligible when the particle size is larger than $0.5 \mu \mathrm{m}$ or the total number concentration of particles is less than 8000 part $\mathrm{cm}^{-3}$. As a consequence, the effect of coagulation was neglected in this study. Furthermore, it is appropriate to measure the particle concentration inside the chamber every $6 \mathrm{~s}$ during $30 \mathrm{~min}$ according to the suggestion in Wang et al. (2018).

During experiments, particles in the chamber may pass through the pores in the textile materials, especially in the window voile fabrics, and deposit on the movable side plates, thus affecting the deposition loss rate coefficient. However, it is possible that only a small amount of particles can pass through the textile materials because of the lower airspeed in the chamber and the "filtration function" of the textile materials. Moreover, due to the interception effect of textile materials, the airflow speed in the space between fabric and movable side plate was very small. Therefore, only very few particles may deposit on the vertical movable side plates during experiments, and their effect on deposition loss rate coefficient is negligible. In addition, it has been confirmed that the particle deposition on fan blades is a negligible factor affecting the deposition loss rate coefficient and will not change significantly with increasing RPM of the fan (Byrne et al., 1995; Thatcher et al., 2002). The observed increase in deposition loss rate coefficient at higher airspeed is due to the increased particle deposition on tested samples and chamber surfaces rather than the fan blades.

\section{RESULTS AND DISCUSSION}

\section{Temperature and Humidity Conditions during Experiments}

In order to avoid the influence of ambient temperature and humidity variations on the temperature and relative humidity inside the chamber, the test chamber was insulated against heat using a polyurethane foam. This is particularly important for studying the particle deposition since it can reduce the effect of thermophoresis (Lai et al., 2002). Therefore, because of the lower power $(<25 \mathrm{w})$ and shorter 
operating time of the only heat source in the chamber-fan, the change of temperature and relative humidity within the chamber during each experiment did not exceed $1^{\circ} \mathrm{C}$ and $1 \%$, respectively. In addition, since the temperature and relative humidity inside the chamber could not be regulated artificially, their initial values at the beginning of each experiment were determined by the outer environment condition. Hence, to maintain similar initial temperature and relative humidity for different experiments, all the experiments were conducted continuously during a concentrated period under a stable climate condition. In summary, all the experiments in this study were carried out within a temperature range of $21.1-31.7^{\circ} \mathrm{C}$ and relative humidity range of $14-19 \%$ with very small variations during each measurement.

Because of relatively low values of relative humidity and easy electrostatic nature of polyester material, a large number of electrostatic charges may accumulate on the surfaces of textile samples and affect the particle deposition during experiments. To remove these electrostatic charges, six fine copper wires, represented by the dashed line in Fig. 3(c), were mounted on the movable side plate. These copper wires contacted with the textile materials during experiments to remove the electrostatic charges from textile surfaces to the movable side plate. Since the walls of the chamber were electrically grounded, the electrostatic charges on the textile surfaces were removed through these conductive metal materials during experiments. It should be noted that not all the electrostatic charges can be removed thoroughly from textile surfaces with this method. But, because all the experiments in this study were carried out under nearly the same environmental conditions, it can be considered that the effects of electrostatic force on particle deposition during these experiments were similar. Thus, according to Hamdani et al. (2008), a comparative analysis of particle deposition on different textile surfaces was achieved in this study.

\section{Particle Deposition versus Airflow Velocity and Particle Size}

The velocity of the upward airflow within the test chamber was varied by means of adjusting the voltage of the fan positioned in the middle of the chamber. Three different speeds of the fan, resulting in three different airflow intensities, were adopted to investigate the influence of airflow velocity on the particle deposition in this study: angular velocity of 955, 1273, and $2800 \mathrm{rpm}$ (revolutions per minute). According to Thatcher et al. (1996), the characteristics of airflow near the surface are the main factors that can directly affect the particle deposition. Therefore, the mean airflow velocity at $3 \mathrm{~cm}$ away from the textile surface was measured using a hot-wire anemometer (Testo 425) at nine locations shown in Fig. 3(c). At least three repeated measurements of the airspeed for each of the nine points were carried out through an additional set of experiments without particle injection. Table 2 shows the average and standard deviation of the near-surface airspeed in both left and right sides under three angular velocities of the fan. The standard deviation represents the variation of airspeeds among the different measurement locations. The results confirmed that the near-surface airspeeds of the samples in left and right sides were consistent with the mean values of $0.40-0.59 \mathrm{~m} \mathrm{~s}^{-1}$ and $0.37-0.54 \mathrm{~m} \mathrm{~s}^{-1}$, respectively.

It is very important for the airflow characteristics within the test chamber to be similar to that in real indoor environments. The airspeeds in typical indoor environments have been extensively measured (Matthews et al., 1989; Haghighat et al., 1999). However, the obtained results in these measurements differ greatly from each other. Thatcher et al. (2002) attributed this to the different type of ventilation and where the measurement was taken within the room. In addition, the previous studies were mainly focused on the mean core airspeed of the indoor environments, and rarely measured the airspeed near the building internal surfaces. Therefore, it is difficult to find in literatures the near-surface airspeeds of curtain measured in actual rooms to compare with that measured in the chamber. However, because the curtains are hung beside the window, the airspeed near their surfaces is related to many indoor and outdoor factors, such as opening or closing of the window, airspeed outside the window, ventilation type in the room, etc. Therefore, the near-surface airspeed of curtains in real indoor environments must fluctuate in a large range for different buildings. Thus, it can be inferred that the airspeed measured in the chamber and shown in Table 2 should be included in the near-surface airspeeds of curtain in actual indoor environments.

Fig. 4 shows the deposition loss rate coefficient of particles on Samples A-D under three different airflow velocities. The same trends were also observed for Samples E-H. The experimental data presented in Fig. 4 indicate that the higher airflow velocity near the textile surface can cause larger deposition loss rate coefficient. In addition, another trend was also observed in Fig. 4: Particle size has a significant effect on deposition loss rate coefficient. The deposition loss rate coefficient tends to decrease as particle size increases from 0.37 to $0.54 \mu \mathrm{m}$, and then begin to increase with the increase of particle size. This can be explained by the dominant deposition mechanism for particles in different sizes. With the decrease of size for smaller particles, the effect of their dominant deposition

Table 2. Average airspeed near the sample surfaces for the three fan voltages.

\begin{tabular}{llllll}
\hline $\begin{array}{l}\text { Fan voltage } \\
(\mathrm{V})\end{array}$ & $\begin{array}{l}\text { Angular velocity } \\
(\mathrm{rpm})\end{array}$ & $\begin{array}{l}\text { Average airspeed left } \\
\left(\mathrm{m} \mathrm{s}^{-1}\right)\end{array}$ & $\begin{array}{l}\text { Standard deviation } \\
\left(\mathrm{m} \mathrm{s}^{-1}\right)\end{array}$ & $\begin{array}{l}\text { Average airspeed right } \\
\left(\mathrm{m} \mathrm{s}^{-1}\right)\end{array}$ & $\begin{array}{l}\text { Standard deviation } \\
\left(\mathrm{m} \mathrm{s}^{-1}\right)\end{array}$ \\
\hline 75 & 955 & 0.40 & 0.16 & 0.37 & 0.18 \\
100 & 1273 & 0.54 & 0.20 & 0.48 & 0.16 \\
220 & 2800 & 0.59 & 0.21 & 0.54 & 0.12 \\
\hline
\end{tabular}



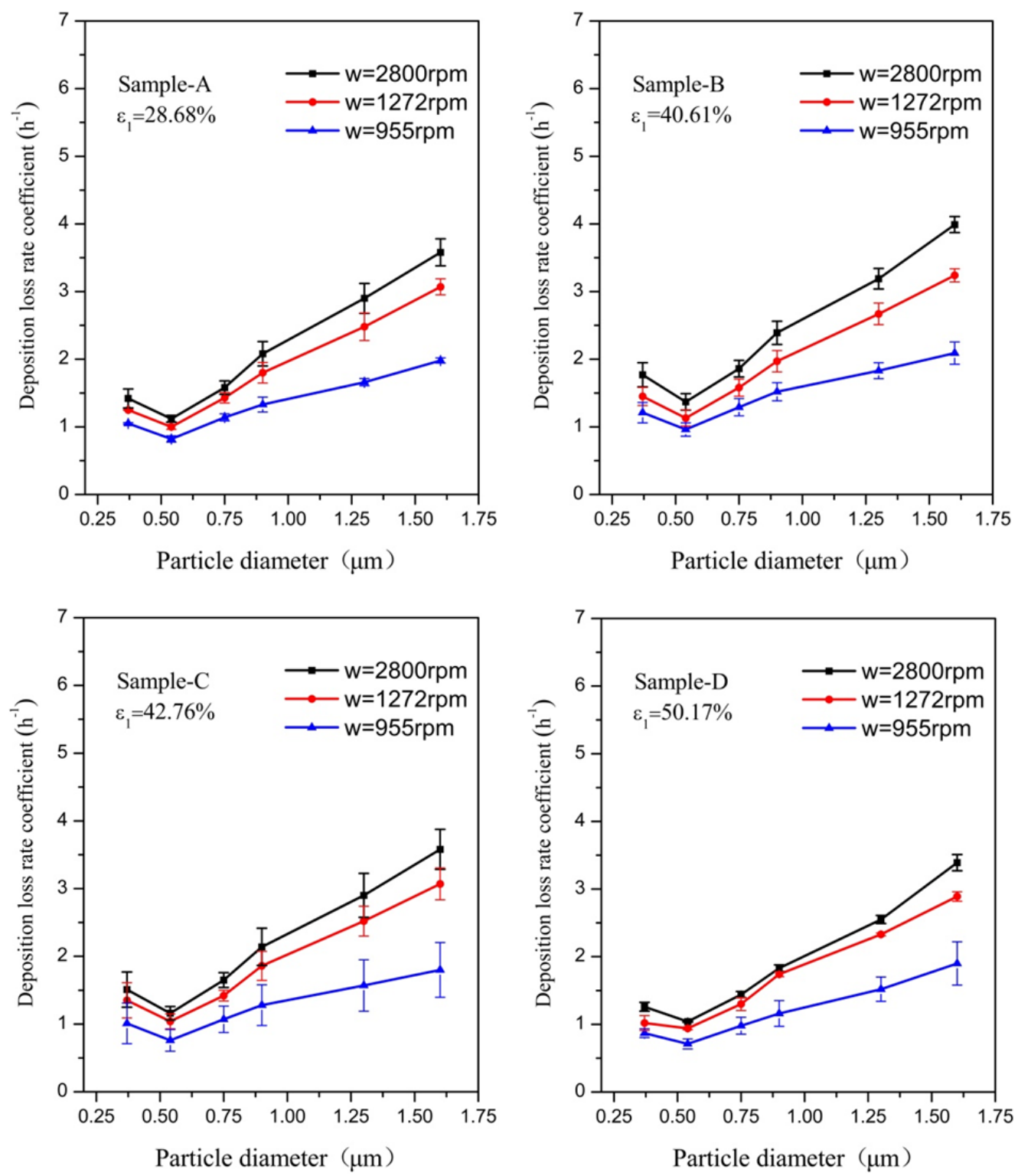

Fig. 4. Deposition loss rate coefficient versus airflow velocity for samples A to D.

mechanism of turbulence and Brownian diffusion on particles is enhanced, and hence the deposition loss rate coefficient increases gradually. Meanwhile, with the increase of size for larger particles, the effect of their dominant deposition mechanism of gravitational settling on particles is enhanced, and so the deposition loss rate coefficient also increases gradually. Therefore, there should be a particle size corresponding to a minimum deposition loss rate coefficient, on which the combined effects of diffusion and gravitational settling are the smallest. As a consequence, there is a V-shaped distribution for the deposition loss rate coefficient with the increase of particle size.

\section{The Effect of Textile Porosity on Particle Deposition}

The surface roughness is an important factor affecting the particle deposition. SMD is the surface mean deviation and indicates the roughness characteristic of the fabric surface (Sun and Stylios, 2006). When selecting samples, the SMD values of all the textile fabrics were measured and the materials whose SMD are close were chosen as tested samples (Table 1). Therefore, the effect of surface roughness on particle deposition in this study can be neglected, and the only concern that may affect particle deposition is the fabric porosity. Because the pores in window voile fabrics are mainly situated between the yarns, Fig. 5 reveals the effect of inter-yarn porosity on particle deposition under three airflow conditions. Error bars have been voluntarily omitted to improve the clarity of the figures. It can be seen from Fig. 5 that the deposition loss rate coefficient does not change greatly with the increase of fabric porosity, that is to say, the particle deposition was just slightly affected by the inter-yarn porosity.

Another important result observed from Fig. 5 was that the deposition loss rate coefficient of most particles increased firstly and then decreased with the increase of fabric porosity under a constant airflow condition. This is 

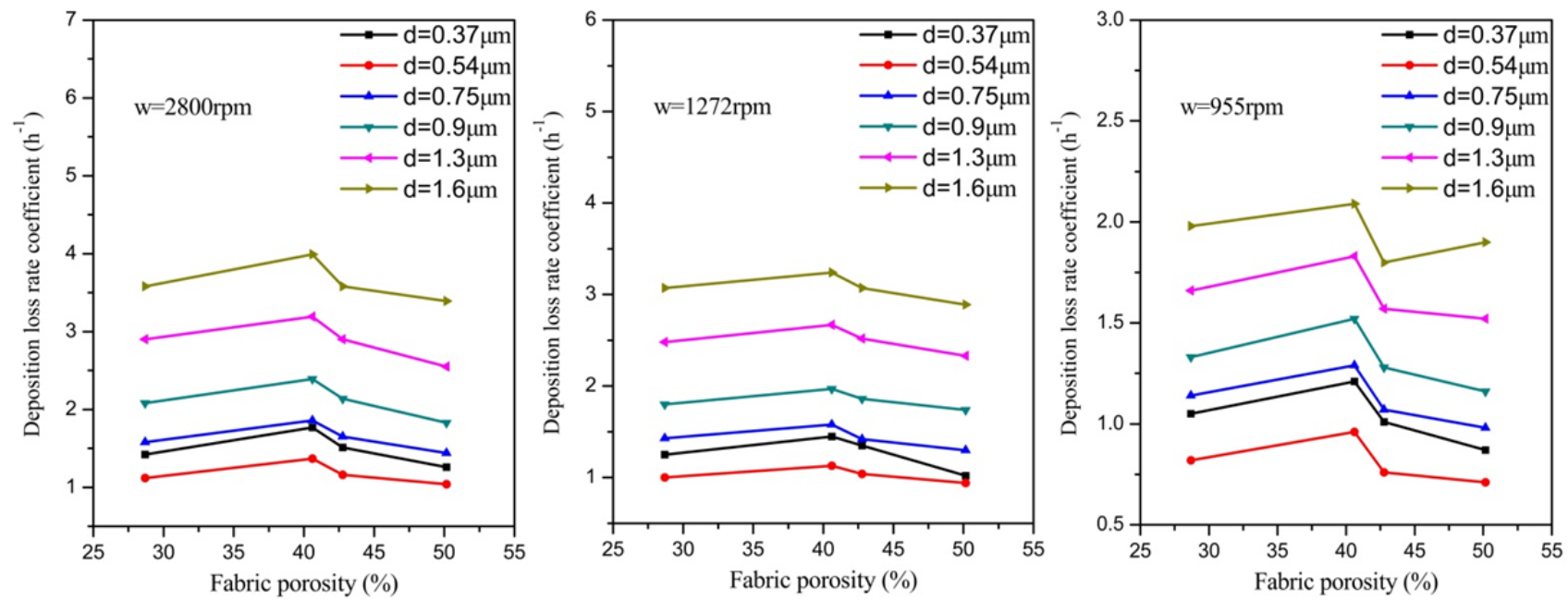

Fig. 5. Deposition loss rate coefficient versus fabric porosity for samples A to D.

related to the variation of airflow velocity passing between the yarns caused by the change of textile porosity. The flow field near the yarns of window voile fabrics can be treated as the flow circling a cylinder. The data in Table 1 indicate that the selected samples of window voile with lower porosity in this study also have smaller spacing between their yarns. Therefore, the airflow speed passing through the pores of the window voile fabrics with lower porosity is small. Correspondingly, the distance between yarns increases with the increase of porosity for Samples A-D, leading to an increase in the airflow velocity passing between the yarns. The increased airspeed will enhance the particle deposition on yarns due to the larger effect of turbulent diffusion. In addition, the viscosity of air makes the flow before and after the cylindrical yarn no longer symmetrical, which may result in vortices appearing behind the cylindrical yarn, and the leeward surface of the yarn becoming the deposition surface of particles under greater airspeed. Therefore, greater airflow speed passing between overall experimental facilities and the factual picture of the $\mathrm{n}$, and thus the deposition loss rate coefficient. Although the increase of porosity can also lead to the decrease of the number of yarns in the fabric per unit area and the decrease of deposition loss rate coefficient, its combined effect still make the deposition loss rate coefficient of particles increase with the increase of porosity. However, further increase of the porosity will not result in significant increase in the airflow velocity passing between yarns as well as the deposition loss rate coefficient when the porosity is large enough. Yet, the number of yarns in the fabric per unit area will still decrease with the increase of porosity, leading to a continued decrease of deposition loss rate coefficient. Therefore, when reaching a certain threshold, further increase of porosity will result in a decrease of deposition loss rate coefficient.

In addition, a different trend for particle deposition under lower airflow intensity was found in Fig. 5. When the fan inside the chamber operated at higher angular velocities ( $\mathrm{w}=2800$ and $1273 \mathrm{rpm}$ ), the deposition loss rate coefficient increased firstly and then decreased with the increase of fabric porosity for all the particle sizes. However, one exception was observed for the deposition loss rate coefficient of $1.6 \mu \mathrm{m}$ particles when the fan operated at the angular velocity of $955 \mathrm{rpm}$. This indicates that the effect of porosity of vertical textile on the deposition of larger particles weakens at lower airflow velocity. In other words, the correlation between the deposition loss rate coefficient of larger particles and the porosity of vertical textiles weakens under lower airflow velocity. This is related to the essence of inter-yarn porosity affecting the particle deposition, namely, changing the inter-yarn porosity can alter the airflow velocity passing between the yarns. When the airspeed near the window voile fabrics is relatively low, the airflow velocity passing between the yarns, as well as its variation caused by the change of porosity, will be even less. Moreover, since particles larger than $1 \mu \mathrm{m}$ are deposited mainly due to gravitational sedimentation, their deposition on the vertical textile surface depending mainly on the turbulent diffusion is quite scarce under lower airspeed. Therefore, the trend of deposition loss rate coefficient for $1.6 \mu \mathrm{m}$ particles under lower near-surface airspeed is different from that of smaller particles or under higher airflow speed.

Table 3 presents the size-dependent particle deposition loss rate coefficient for Samples E-H under the airflow velocity of $\mathrm{w}=1273 \mathrm{rpm}$. The same trends have also been observed for the other two airflow conditions. According to the data shown in Table 1, the total porosity, $\varepsilon_{2}$, is much larger than the inter-yarn porosity, $\varepsilon_{1}$, for Samples E-H, illustrating that the pores in the curtain cloth samples are mainly situated between the fibers because of the compact structure of the curtain cloth. Therefore, the total porosities of the four curtain cloth samples mainly referred to their inter-fiber porosities. The experimental data in Table 3 illustrate that there is no specific correlation between the deposition loss rate coefficient and inter-fiber porosity for this set of samples. This may be related to the disorderly distribution of pores between fibers in the textile material. Generally speaking, the number and size distribution of the pores between fibers in textile are usually uneven because 
of the highly non-uniform organization of the structure and deformation for textiles. Furthermore, it should be noted that only the properties of pores, such as their sizes, orientations and numbers, in the windward surface of textile material can affect the airspeed and particle concentration distribution near the textile surface, and then the particle deposition. These properties of pores in the interior and leeward side of the textile have little effect on the particle deposition. However, as reported by Rebenfeld et al. (1995), porosity is an average physical parameter for porous material, which reflect the fraction of the nominal bulk volume of a material that is occupied by the overall void space in the textile material. According to this definition, the parameter of porosity cannot distinguish whether the pores are in the windward surface, interior or leeward side of the textile material. It is possible that entirely different textile materials can have the same interfiber porosity. Therefore, there is an absence of specific correlation between the deposition loss rate coefficient and inter-fiber porosity for Samples E-H.

In fact, the deposition loss rate coefficient measured in this study according to Eq. (4) is the sum of deposition loss rate coefficient for textile samples and chamber surfaces without textile covers. However, only the deposition loss rate coefficient for the vertical textile samples is the main concern of this study, which can be calculated as follows (Afshari and Reinhold, 2008):

$\lambda_{\text {material }}=\lambda_{\text {chamber }+ \text { material }}-\lambda_{\text {chamber }}$

where $\lambda_{\text {material }}$ is the deposition loss rate coefficient for the vertical textile samples, $\lambda_{\text {chamber+material }}$ is the sum of deposition loss rate coefficient for textile samples and chamber surfaces without textile covers, and $\lambda_{\text {chamber }}$ is the deposition loss rate coefficient for the internal surfaces of the chamber. It is noteworthy that the $\lambda_{\text {material }}$ in Eq. (5) is actually a relative deposition rate representing the deposition loss rate coefficient for textile samples minus that for the chamber surfaces covered by textile samples. To obtain this relative deposition rate for the tested textile samples, $\lambda_{\text {chamber }}$ was measured under three airflow conditions without placing any textile sample in the chamber. Then, the $\lambda_{\text {material }}$ values for Samples A-D under three airflow conditions were calculated according to Eq. (5) and shown in Fig. 6. Comparing the experimental data in Fig. 6 with that in Fig. 5 , the same trend of $\lambda_{\text {material }}$ and $\lambda_{\text {chamber+material }}$ was observed for Samples A-D. This is because the particles with identical sizes have the same values of $\lambda_{\text {chamber }}$ under constant airflow intensity. Thus, after subtracting the same value of $\lambda_{\text {chamber }}$ from the $\lambda_{\text {chamber+material }}$ of different textile samples, the trend of the obtained $\lambda_{\text {material }}$ with the increase of fabric porosity was still the same as that of $\lambda_{\text {chamber+material }}$. Therefore, it can be inferred that the relative deposition rate $\lambda_{\text {material }}$ for Samples $\mathrm{E}-\mathrm{H}$ still has no specific correlation with the inter-fiber porosity. In addition, it is interesting to notice that there are many negative values for $\lambda_{\text {material }}$ of Samples A-D in Fig. 6, illustrating that the deposition of some particles on window voile samples are less than that on the smooth internal surfaces of the chamber. This may be caused by the large number of via holes in the window voile fabrics, which made the surface area of particle deposition on the window voile fabrics less than that on the corresponding chamber surfaces.

Table 3. Deposition loss rate coefficient of samples E-H under airflow velocity of $\mathrm{w}=1273 \mathrm{rpm}$.

\begin{tabular}{lllllll}
\hline Sample No. & $0.37(\mu \mathrm{m})$ & $0.54(\mu \mathrm{m})$ & $0.75(\mu \mathrm{m})$ & $0.9(\mu \mathrm{m})$ & $1.3(\mu \mathrm{m})$ & $1.6(\mu \mathrm{m})$ \\
\hline $\mathrm{E}\left(\varepsilon_{2}=72.03 \%\right)$ & $2.86 \pm 0.44$ & $2.24 \pm 0.40$ & $2.85 \pm 0.36$ & $3.29 \pm 0.33$ & $3.87 \pm 0.29$ & $4.50 \pm 0.27$ \\
$\mathrm{~F}\left(\varepsilon_{2}=66.64 \%\right)$ & $1.82 \pm 0.09$ & $1.41 \pm 0.02$ & $1.83 \pm 0.02$ & $2.44 \pm 0.04$ & $3.10 \pm 0.06$ & $3.74 \pm 0.02$ \\
$\mathrm{G}\left(\varepsilon_{2}=65.70 \%\right)$ & $2.64 \pm 0.06$ & $2.07 \pm 0.07$ & $2.67 \pm 0.10$ & $3.11 \pm 0.06$ & $3.64 \pm 0.05$ & $4.33 \pm 0.04$ \\
$\mathrm{H}\left(\varepsilon_{2}=63.22 \%\right)$ & $1.88 \pm 0.01$ & $1.57 \pm 0.02$ & $2.02 \pm 0.03$ & $2.53 \pm 0.04$ & $3.15 \pm 0.03$ & $3.80 \pm 0.03$ \\
\hline
\end{tabular}
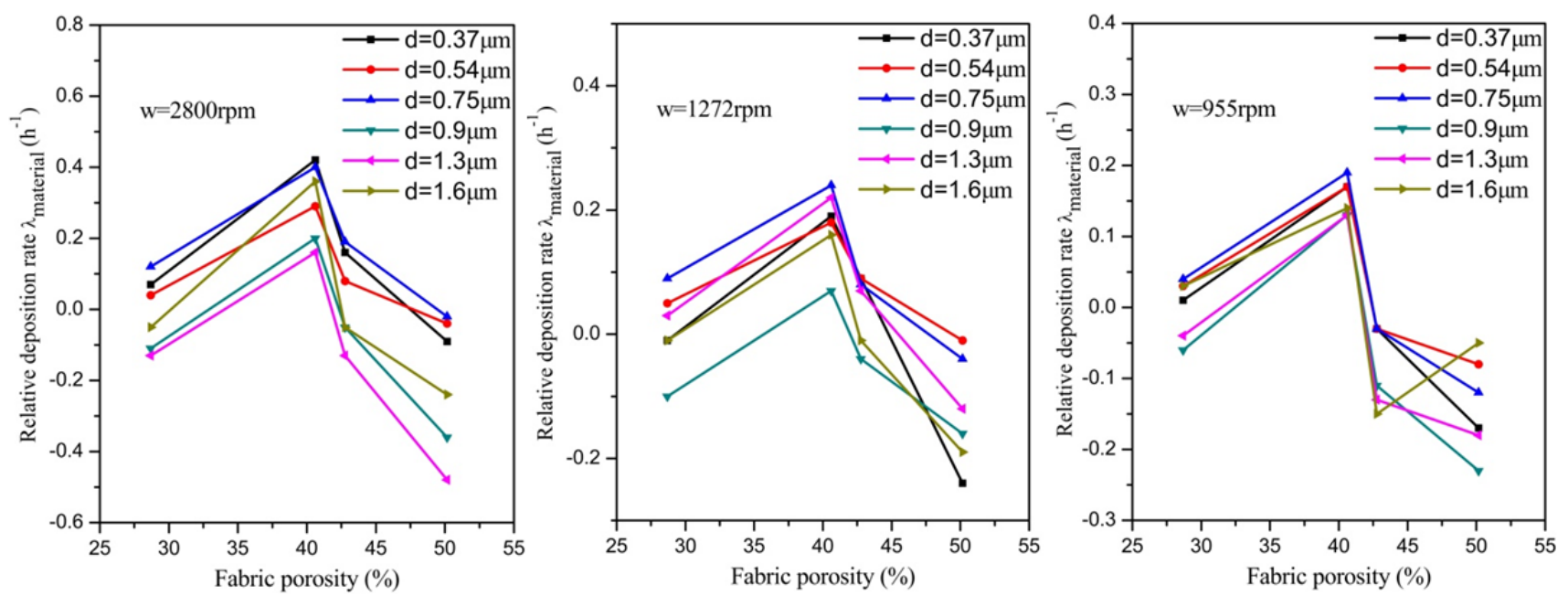

Fig. 6. Relative deposition rate $\lambda_{\text {material }}$ versus fabric porosity for samples A to D. 


\section{CONCLUSION}

To study the effect of the porosity of vertical textile materials on particle deposition, the deposition loss rate coefficients of six particle sizes ranging from 0.37 to 1.6 $\mu \mathrm{m}$ were measured under three airflow conditions. Based on the experimental data generated in this study, the following conclusions can be drawn:

(1) The deposition loss rate coefficient is an increasing function of the near-surface airflow velocity, initially decreasing but then increasing as the particle size increases.

(2) For most particles, the deposition loss rate coefficient first increases and then decreases as the inter-yarn porosity increases.

(3) There is no specific correlation between the deposition loss rate coefficient and the inter-fiber porosity of textiles.

(4) The correlation between the deposition loss rate coefficient and the porosity of vertical textile materials may weaken for larger particles and at lower nearsurface airspeeds.

Finally, many other surface properties that are specific to textiles, such as the density and length of hairiness on textile surface, may significantly affect the particle deposition. Therefore, the authors suggest that future experimental studies on particle deposition explore the effects of these properties.

\section{ACKNOWLEDGEMENT}

This study is supported by National Science Foundation of China, No. 51678469.

\section{REFERENCES}

Abadie, M., Limam, K. and Allard, F. (2001). Indoor particle pollution: Effect of wall textures on particle deposition. Build. Environ. 36: 821-827.

Afshari, A. and Reinhold, C. (2008). Deposition of fine and ultrafine particles on indoor surface materials. Indoor Built Environ. 17: 247-251.

Azar, E., Nikolopoulou, C. and Papadopoulos, S. (2016). Integrating and optimizing metrics of sustainable building performance using human-focused agent-based modeling. Appl. Energy 183: 926-937.

Byrne, M.A., Goddard, A.J.H., Lange, C. and Roed, J. (1995). Stable tracer aerosol deposition measurements in a test chamber. J. Aerosol Sci. 26: 645-653.

Çay, A., Atav, R. and Duran, K. (2007). Effects of warpweft density variation and fabric porosity of the cotton fabrics on their colour in reactive dyeing. Fibres Text. East. Eur. 15: 91-94.

Chen, X. and Li, A. (2014). An experimental study on particle deposition above near-wall heat source. Build. Environ. 81: 139-149.

Chen, X., Li, A. and Gao, R. (2014). Numerical investigation on particle deposition in a chamber with an attached-wall heat source. Indoor Built Environ. 23:
640-652.

Delgado-Saborit, J.M., Aquilina, N.J., Meddings, C., Baker, S. and Harrison, R.M. (2011). Relationship of personal exposure to volatile organic compounds to home, work and fixed site outdoor concentrations. Sci. Total Environ. 409: 478-488.

Haghighat, F. and Donnini, G. (1999). Impact of psychosocial factors on perception of the indoor air environment studies in 12 office buildings. Build. Environ. 34: 479-503.

Hamdani, S.E., Limam, K., Abadie, M.O. and Bendou, A. (2008). Deposition of fine particles on building internal surfaces. Atmos. Environ. 42: 8893-8901.

Hsieh, Y. (1995). Liquid transport in fabric structures. Text. Res. J. 65: 299-307.

Hussein, T., Hämeri, K., Heikkinen, M.S.A. and Kulmala, M. (2005). Indoor and outdoor particle size characterization at a family house in Espoo-Finland. Atmos. Environ. 39: 3697-3709.

Hussein, T., Hruška, A., Dohányosová, P., Džumbová, L., Hemerka, J., Kulmala, M. and Smolík, J. (2009a). Deposition rates on smooth surfaces and coagulation of aerosol particles inside a test chamber. Atmos. Environ. 43: 905-914.

Hussein, T., Kubincová, L., Džumbová, L., Hruška, A., Dohányosová, P., Hemerka, J. and Smolík, J. (2009b). Deposition of aerosol particles on rough surfaces inside a test chamber. Build. Environ. 44: 2056-2063.

Lai, A.C.K. (2002). Particle deposition indoors: A review. Indoor Air 12: 211-214.

Lai, A.C.K. and Nazaroff, W.W. (2000). Modeling indoor particle deposition from turbulent flow onto smooth surfaces. J. Aerosol Sci. 31: 463-476.

Lai, A.C.K., Byrne, M.A. and Goddard, A.J.H. (2002). Experimental studies of the effect of rough surfaces and air speed on aerosol deposition in a test chamber. Aerosol Sci. Technol. 36: 973-982.

Lai, A.C.K. and Nazaroff, W.W. (2005). Supermicron particle deposition from turbulent chamber flow onto smooth and rough vertical surfaces. Atmos. Environ. 39: 4893-4900.

Liu, Z., Cheng, K., Li, H., Cao, G., Wu, D. and Shi, Y. (2018a). Exploring the potential relationship between indoor air quality and the concentration of airborne culturable fungi: A combined experimental and neural network modeling study. Environ. Sci. Pollut. Res. Int. 25: 3510-3517.

Liu, Z., Ma, S., Cao, G., Meng, C. and He, B.J. (2018b). Distribution characteristics, growth, reproduction and transmission modes and control strategies for microbial contamination in HVAC systems: A literature review. Energy Build. 177: 77-95.

Matthews, T.G., Thompson, C.V., Wilson, D.L. and Hawthorne, A.R. (1989). Air velocities inside domestic environments: An important parameter in the study of indoor air quality and climate. Environ. Int. 15: 545-550.

Nazaroff, W.W. and Cass, G.R. (1991). Protecting museum collections from soiling due to the deposition of airborne particles. Atmos. Environ. 25: 841-852. 
Nazaroff, W.W., Gadgil, A.J. and Weschler, C.J. (1993). Critique of the use of deposition velocity in modeling indoor air quality. In: Modeling of indoor air quality and exposure, Nadga, N.L. (Ed.), ASTM STP 1205, American Society for Testing and Material, Philadelphia, PA, 1993, pp. 81-104.

Qiao, T., Zhao, M., Xiu, G. and Yu, J. (2016). Simultaneous monitoring and compositions analysis of $\mathrm{PM}_{1}$ and $\mathrm{PM}_{2.5}$ in Shanghai: Implications for characterization of haze pollution and source apportionment. Sci. Total Environ. 557-558: 386-394.

Rebenfeld, L. and Miller, B. (1995). Using liquid flow to quantify the pore structure of fibrous materials. J. Text. Inst. 86: 241-251.

Sun, D. and Stylios, G.K. (2006). Fabric surface properties affected by low temperature plasma treatment. J. Mater. Process. Technol. 173: 172-177.

Tang, L., Yu, H., Ding, A., Zhang, Y., Qin, W., Wang, Z., Chen, W., Hua, Y. and Yang, X. (2016). Regional contribution to $\mathrm{PM}_{1}$ pollution during winter haze in Yangtze River Delta, China. Sci. Total Environ. 541: 161-166.

Thatcher, T.L., Fairchild, W.A. and Nazaroff, W.W. (1996). Particle deposition from natural convection enclosure flow onto smooth surfaces. Aerosol Sci. Technol. 25: 359-374.

Thatcher, T.L., Lai, A.C.K., Moreno-Jackson, R., Sextro, R.G. and Nazaroff, W.W. (2002). Effects of room furnishings and air speed on particle deposition rates indoors, Atmos. Environ. 36: 1811-1819.

Vette, A.F., Rea, A.W., Lawless, P.A., Rodes, C.E., Evans, G., Highsmith, V.R. and Sheldon, L. (2001).
Characterization of indoor-outdoor aerosol concentration relationships during the Fresno PM exposure studies. Aerosol Sci. Technol. 34: 118-126.

Wang, S.J. (2012). Effects of surface roughness on the indoor particle deposition rate constant. Ph.D. thesis. Syracuse University, New York, USA.

Wang, Y., Fan, X.W., Li, A., Shang, L.Y. and Wang, H. (2018). Deposition of fine particles on vertical textile surfaces: A small-scale chamber study. Build. Environ. 135: 308-317.

Weschler, C.J., Shields, H.C. and Shah, B.M. (1996). Understanding and reducing the indoor concentration of submicron particles at a commercial building in Southern California. J. Air Waste Manage. Assoc. 46: 291-299.

Xiao, Z., Zhang, Y., Hong, S., Bi, X., Jiao, L., Feng, Y. and Wang, Y. (2011). Estimation of the main factors influencing haze, based on a long-term monitoring campaign in Hangzhou, China. Aerosol Air Qual. Res. 11: 873-882.

Xu, M., Nematollahi, M., Sextro, R.G., Gadgil, A.J. and Nazaroff, W.W. (1994). Deposition of tobacco smoke particles in a low ventilation room. Aerosol Sci. Technol. 20: 194-206.

Zhao, B. and Wu, J. (2007). Particle deposition in indoor environments: Analysis of influencing factors. J. Hazard. Mater. 147: 439-448.

Received for review, August 30, 2018 Revised, October 31, 2018 Accepted, November 23, 2018 